\title{
TIME DEPENDENT DEBONDING OF ALUMINUM/ALUMINA INTERFACES UNDER CYCLIC AND STATIC LOADING
}

\author{
J. J. Kruzic, J. M. McNaney, R. M. Cannon, and R. O. Ritchie \\ Materials Sciences Division, Lawrence Berkeley National Laboratory \\ and \\ Department of Materials Science and Engineering, \\ University of California, Berkeley, CA 94720-1760, USA
}

January 2001

submitted to

Structure-Property Relationships of Oxide Surfaces and Interfaces

Work supported by the Director, Office of Science, Office of Basic Energy Sciences, Materials

Sciences Division of the U.S. Department of Energy under Contract No. DE-AC03-76SF00098. 


\title{
Time Dependent Debonding of Aluminum/Alumina Interfaces under Cyclic and Static Loading
}

\author{
J. J. Kruzic, J. M. McNaney, R. M. Cannon, and R. O. Ritchie \\ Materials Sciences Division, Lawrence Berkeley National Laboratory, and Department of \\ Materials Science and Engineering, University of California, Berkeley, CA 94720
}

\begin{abstract}
The structural integrity of oxide/metal interfaces is important in many applications. While most attention has focused on the debonding of oxide/metal interfaces by conducting strength and fracture toughness tests, very few investigations have looked at time dependant failure of interfaces under cyclic or static loading. Tests have been conducted on sandwich specimens consisting of 5 - 100 micron thick aluminum layers bonded between either polycrystalline or single crystal $\mathrm{Al}_{2} \mathrm{O}_{3}$ to determine cyclic fatigue-crack growth, as well as static loaded moistureassisted crack-growth, properties of $\mathrm{Al} / \mathrm{Al}_{2} \mathrm{O}_{3}$ interfaces. Under cyclic loading, crack growth was observed to occur predominantly by interfacial debonding, but was also observed to make excursions into the $\mathrm{Al}_{2} \mathrm{O}_{3}$. Static loading in a moist environment also caused interfacial cracks to deviate into the $\mathrm{Al}_{2} \mathrm{O}_{3}$ or alternatively to arrest. Due to the poor crack growth resistance of the $\mathrm{Al}_{2} \mathrm{O}_{3}$, cracks leaving the interface grew at faster rates than those at the interface. Trends in crack trajectories and crack growth rates are explained in terms of the degree of plastic constraint in the aluminum layer, the modulus mismatch, and the effects of environmental mechanisms.
\end{abstract}

\section{INTRODUCTION}

Oxide/metal interfaces can be found in many engineering applications including microelectronic packaging, multi-layered films, coatings, joints, and composite materials. In order to design reliable engineering systems using such bimaterial interfaces, the structural integrity of the interface must be maintained over the lifetime of the component. While much research has been conducted on the strength and fast fracture behavior of oxide/metal interfaces [1-15], previous work is limited to only a handful of studies that focused on time dependent crack growth at and near interfaces, specifically, fatigue crack growth under cyclic loading [1619] and moisture-assisted crack growth under static loading [20-23]. Additionally, layered material systems are quite common, and in metal layers, plastic deformation is often constrained by the oxide when plasticity extends across the entire layer during failure. Indeed, theoretical investigations have predicted that the plastic zone size, the crack tip opening displacement, and the stress state near a crack tip are affected by the change in plastic constraint of the metal layer due to variations in the layer thickness [14]. There have been, however, very few experimental investigations as to how failure mechanisms are affected by these changes $[2,8,15,17]$. Trends of increasing strength with decreasing layer thickness in the $\mathrm{Al} / \mathrm{Al}_{2} \mathrm{O}_{3}$ system have been observed [2], while studies centered on fatigue crack growth properties showed no conclusive trends over the range of metal layer thicknesses studied $(100-500 \mu \mathrm{m})$ [17]. Fracture toughness was suspected to decrease with decreasing layer thickness; however, this trend was obscured due to excessive plasticity in the $100-500 \mu \mathrm{m}$ thick metal layers [17]. In light of this, the current paper is focused on further investigation into the role of constraint of the metal on interface failure, with particular emphasis on time dependent crack growth at $\mathrm{Al} / \mathrm{Al}_{2} \mathrm{O}_{3}$ interfaces. 


\section{EXPERIMENTAL PROCEDURES}

Liquid state bonding was used to make sandwich specimens with 5, 35, and $100 \mu \mathrm{m}$ thick layers of $99.999 \%$ pure aluminum bonded between $99.5 \%$ pure polycrystalline $\mathrm{Al}_{2} \mathrm{O}_{3}$. Blocks of Coors $\mathrm{AD} 995 \mathrm{Al}_{2} \mathrm{O}_{3}(21.3 \mathrm{~mm}$ square by $10.2 \mathrm{~mm}$ thick) were lapped flat to a $1 \mu \mathrm{m}$ finish and carefully cleaned. High purity (99.999\%) aluminum foils (100 and $35 \mu \mathrm{m}$ thick layers) or evaporated coatings ( $5 \mu \mathrm{m}$ thick layers) were placed between two $\mathrm{Al}_{2} \mathrm{O}_{3}$ blocks and cold pressed to $\sim 40 \mathrm{MPa}$ before placing in a closed, high purity $\mathrm{Al}_{2} \mathrm{O}_{3}$ crucible for bonding. Bonding was carried out in a purified argon environment at a temperature of $980^{\circ} \mathrm{C}$, held for 5 minutes before cooling. Further processing details can be found elsewhere [2]. Bonded blocks were machined into $3 \mathrm{~mm}$ thick compact tension $\mathrm{C}(\mathrm{T})$ specimens for mechanical testing. Preliminary experiments were also conducted using single crystal $\mathrm{Al}_{2} \mathrm{O}_{3}$ (sapphire) substrates in a double cantilever beam geometry.

Fatigue-crack growth rates were measured in room air at $25^{\circ} \mathrm{C}(20-40 \%$ relative humidity $)$ in general accordance with ASTM standard E647. Tests were conducted at a frequency of $25 \mathrm{~Hz}$ (sine wave) using servo-hydraulic testing machines at a positive, constant load ratio (ratio of minimum to maximum loads) of $R=0.1$. Crack lengths were continuously monitored using compliance methods via back face strain gauges. Crack driving forces were assessed using the range of strain energy release rate, $\Delta G=G_{\max }-G_{\min }$, with $G$ approximated from asymptotic stress intensity solutions for monolithic samples, which is an accurate approximation in the linear elastic limit for the layer thicknesses used in this study. Fatigue thresholds, $\Delta G_{\mathrm{TH}}$, were defined as the applied $\Delta G$ corresponding to growth rates below $\sim 10^{-10} \mathrm{~m} / \mathrm{cycle}$. After fatigue testing, fracture toughness tests were also carried out on the $\mathrm{C}(\mathrm{T})$ samples to assess trends in fracture toughness with changing constraint from the variations in layer thickness.

Similar moisture-assisted crack growth experiments were conducted on fatigue pre-cracked specimens in a controlled high humidity ( $>95 \%$ relative humidity) room air environment. High humidity was maintained by bubbling room air twice through distilled water and into a closed testing chamber. Samples were tested under constant load with crack driving forces assessed using the strain energy release rate, $G$. Crack lengths were monitored in situ using back face strain techniques to determine crack velocity, $d a / d t$, with crack lengths also periodically verified using more accurate unloading compliance methods.

\section{RESULTS}

\section{Fracture Toughness Properties}

Figure 1 shows a trend of decreasing toughness with decreasing layer thickness over the range of 5-100 $\mu \mathrm{m}$ for the $\mathrm{Al}_{2} \mathrm{O}_{3} / \mathrm{Al}$ interface $\mathrm{C}(\mathrm{T})$ samples fractured after fatigue testing. In all three cases, the fatigue pre-crack, initially at the interface, initiated brittle failure of the $\mathrm{Al}_{2} \mathrm{O}_{3}$, with the $\mathrm{Al}_{2} \mathrm{O}_{3} / \mathrm{Al}$ interface remaining intact after failure. This trend in toughness has been attributed to the varying amount of crack blunting that occurs as the layer thickness (constraint) changes; indeed, direct evidence of such crack blunting is shown in Figure 2. For thinner layers, less blunting occurs due to the constraint from the $\mathrm{Al}_{2} \mathrm{O}_{3}$, resulting in a sharper crack tip. This implies that at the same applied driving force, samples with thinner, more highly constrained, layers experience higher local stresses near the (sharper) crack tip, and thus failure occurs at lower applied driving forces. Additionally, it should be noted that for the samples with 35 and 


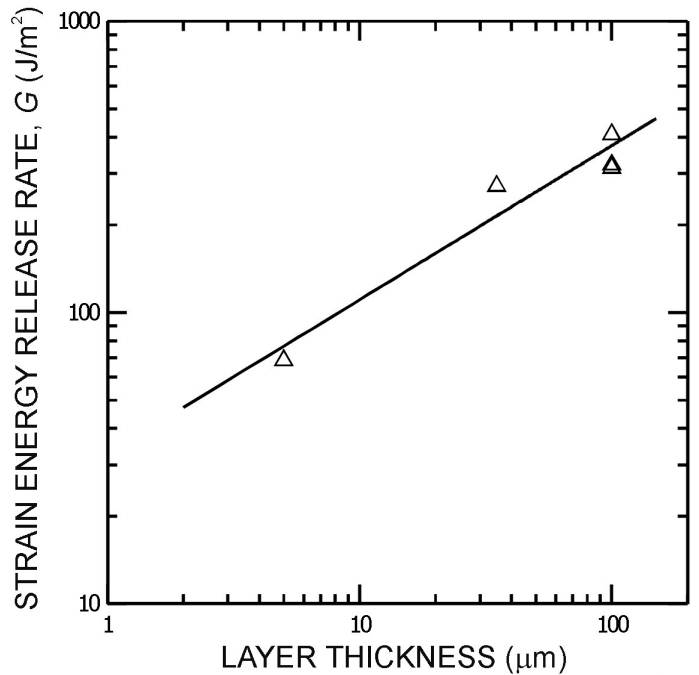

Figure 1. Fracture toughness data showing a decrease in toughness with decreasing aluminum layer thickness. All samples failed in the alumina.

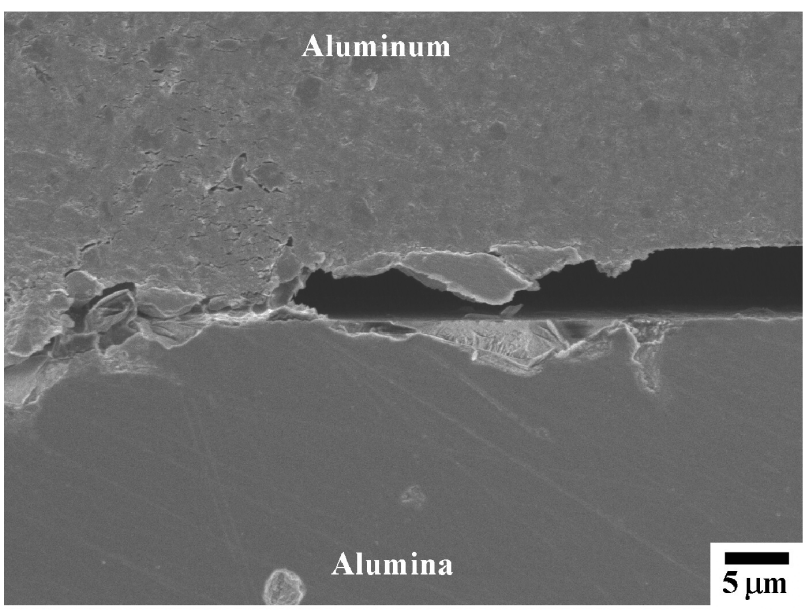

Figure 2. In situ loaded $100 \mu \mathrm{m}$ thick layer sample showing crack blunting into the aluminum layer. Sample was loaded to $460 \mathrm{~J} / \mathrm{m}^{2}$.

$100 \mu \mathrm{m}$ layer thicknesses, the asymptotic driving forces underestimate the fracture energy due to excessive plasticity in the aluminum. Thus, the actual trend would be more pronounced if large scale plasticity were taken into account in the calculation of the crack driving forces.

\section{Fatigue Crack Growth under Cyclic Loads}

Under fatigue loading, failure typically occurred exactly at the interface, with a trend of increasing fatigue resistance with decreasing layer thickness in the near threshold regime (Figure 3). Samples with thinner (more highly constrained) aluminum layers exhibited higher fatigue thresholds and lower growth rates in the near threshold regime. Indeed, samples with $5 \mu \mathrm{m}$ thick layers showed a factor of two increase in fatigue threshold compared to less constrained, $100 \mu \mathrm{m}$ thick layer samples. Additionally, data from reference [17] are shown for samples with 100 $500 \mu \mathrm{m}$ thick layers where no such trend was observed. Observations of the fatigue fracture surface revealed evidence of fatigue striations on the aluminum side of the fracture surface (Figure 4). Such striations suggest a mechanism of fatigue failure similar to that of ductile metals, with crack advance occurring during a process that involves blunting and re-sharpening of the crack tip, with individual striation markings corresponding to each blunting event. The amount of crack advance per cycle is directly related to the amount of blunting at the crack tip, and thus if less blunting occurs per cycle due to constraint, there is less crack advance per cycle. While this gives rise to higher fatigue resistance for the more highly constrained samples in this study, it is important to note that for layers thicknesses $\geq 100 \mu \mathrm{m}$, the computed plastic zone thickness ahead of the crack tip at a bimaterial interface is small enough $\left(\sim 35 \mu \mathrm{m}\right.$ at $4 \mathrm{~J} / \mathrm{m}^{2}$ [9] $)$ to be unconstrained at the fatigue threshold, $\Delta G_{\mathrm{TH}}$, and thus no effect of layer thickness (constraint) would be expected in this range.

For the most highly constrained, $5 \mu \mathrm{m}$ thick layer samples, examination of the fatigue surface after failure revealed crack jumping from one interface to the other during growth. Examination of unfractured samples showed these jumps to be predominantly initiated at flaws in the alumina microstructure. As preliminary experiments to suppress crack jumping using 


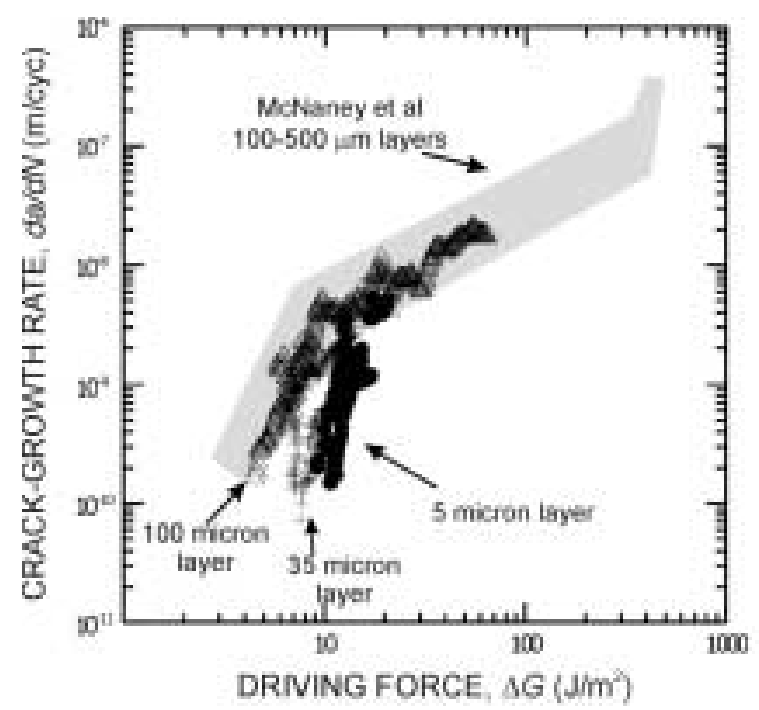

Figure 3. Fatigue crack growth results showing crack growth resistance decreasing with increasing layer thickness from $5-100 \mu \mathrm{m}$ in the near threshold regime. Crack growth was at the interface for all data shown. Additional data from ref. [17].

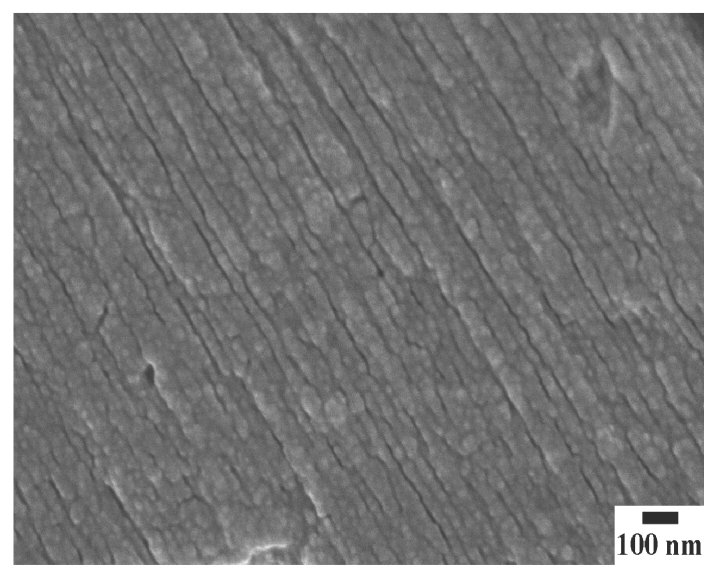

Figure 4. Evidence of fatigue striations on aluminum side of fatigue fracture surface. Direction of crack growth was left to right.

sapphire substrates have shown the same trend of increased fatigue threshold levels with decreasing layer thickness, crack jumping did not appear to have a major effect on the results presented here.

Additionally, for the $5 \mu \mathrm{m}$ layer thickness samples, it was found that at higher driving forces the crack left the interface and grew in the alumina (Figure 5). After a short transitory regime, analogous to the short crack regime for ceramic fatigue (e.g., ref. [24]), the data agree well with that for the fatigue of bulk polycrystalline alumina, also shown in Figure 5. Further details on short crack effects in ceramics can be found elsewhere [24-26]. Crack initiation into the alumina for these samples is facilitated by the higher local crack tip stresses due to constraint. While more highly constrained layers show improved fatigue properties in the near threshold regime, at higher driving forces the change in fatigue mechanism from ductile fatigue at the interface to brittle fatigue in the oxide is indeed detrimental to the overall fatigue resistance. It can be concluded, therefore, that care must be taken in determining possible changes in fatigue mechanisms when attempting to optimize oxide/metal layered systems for fatigue critical applications.

\section{Moisture-Assisted Crack Growth under Static Load}

Under static loads, moisture-assisted crack growth along the metal/oxide interface was not observed in any of the samples tested. Instead, crack growth occurred only when interfacial fatigue pre-cracks left the interface to propagate into the alumina for the $5 \mu \mathrm{m}$ thick layer samples at driving forces lower than for similar sized cracks in bulk $\mathrm{Al}_{2} \mathrm{O}_{3}$, again indicating an effect analogous to short crack effects found in ceramic fatigue; growth rates for all samples are shown in Figure 6. For two of the three $35 \mu \mathrm{m}$ thick layer samples, crack growth occurred only at driving forces higher than necessary for bulk $\mathrm{Al}_{2} \mathrm{O}_{3}$, with the higher driving forces causing rapid failure, thereby making data collection quite difficult. In the case of $100 \mu \mathrm{m}$ thick layers (and one sample with a $35 \mu \mathrm{m}$ thick layer), no crack growth was observed at measurable rates 


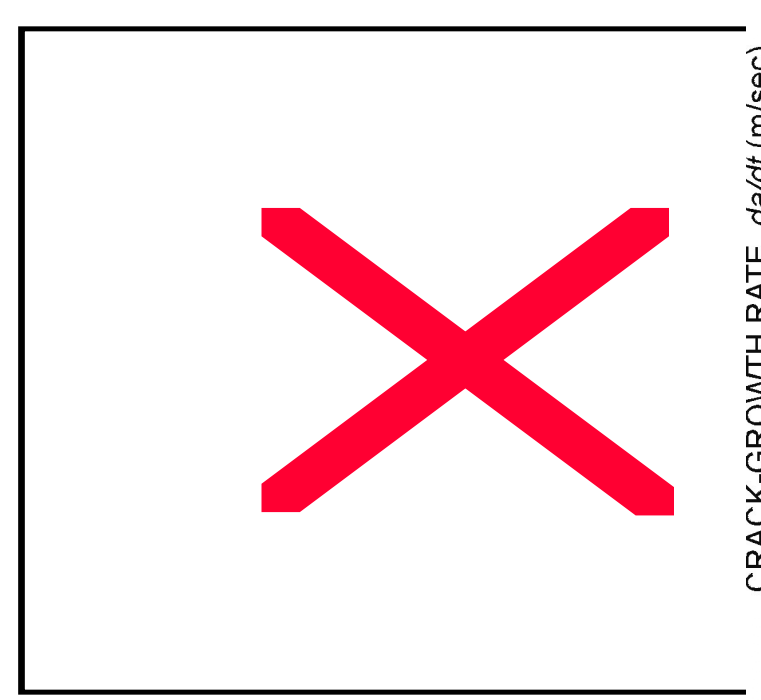

Figure 5. Fatigue crack growth results for a crack leaving the interface of a $5 \mu \mathrm{m}$ thick layer sample at higher driving forces. Growth rates accelerated before slowing and merging with bulk alumina data. Additional data from ref. [17].

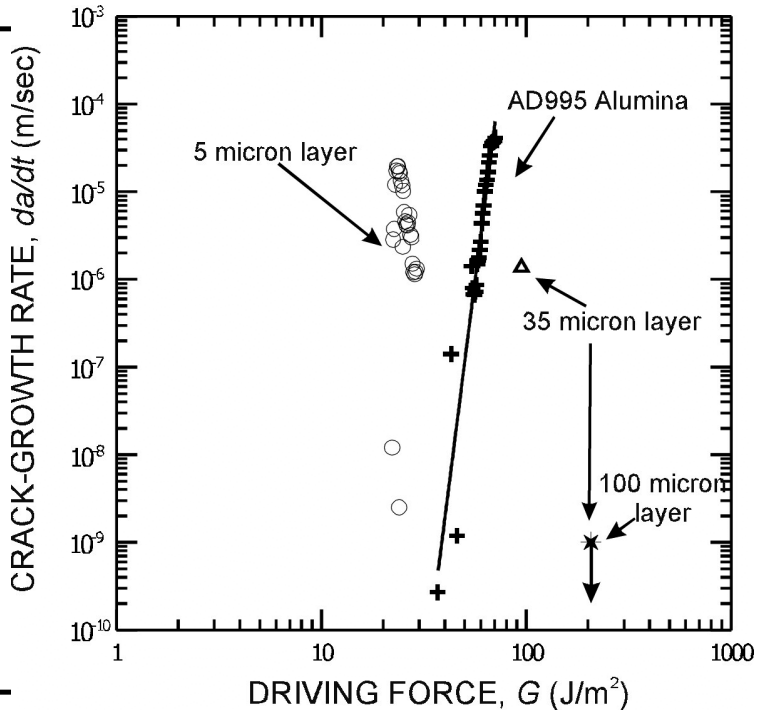

Figure 6. Moisture-assisted crack growth results for interface and bulk alumina specimens. Crack growth was in the alumina for all cases in which crack growth occurred. Tests were conducted in room air with $>95 \%$ relative humidity under static load.

(> $10^{-9} \mathrm{~m} / \mathrm{sec}$.) up to driving forces of $\sim 200 \mathrm{~J} / \mathrm{m}^{2}$. The higher resistance to moisture-assisted crack propagation for less constrained samples is attributed to increased crack tip blunting that lowers the local crack tip stresses below the minimum value necessary for the crack to leave the interface and enter the $\mathrm{Al}_{2} \mathrm{O}_{3}$.

The observed crack growth for the interface specimens was primarily intergranular in the alumina, and appeared to be identical to observed intergranular moisture-assisted crack growth in bulk alumina [27]. Although no interfacial moisture-assisted crack growth was observed, the interface may be nonetheless susceptible to moisture-assisted crack growth under conditions of reduced crack blunting and/or reduced propensity for cracking into the oxide substrate. While the first condition may be met by decreasing the metal layer thickness and/or increasing the metal yield strength, the latter condition may be achieved by decreasing the flaw population at the interface and in the oxide substrate. Preliminary experiments using sapphire substrates, where few substrate flaws exist, have demonstrated that no interfacial moisture-assisted crack growth occurs for $10 \mu \mathrm{m}$ thick layers; however, thinner layers may be necessary to achieve high enough local stresses to activate this possible failure mechanism.

\section{CONCLUSIONS}

Changing constraint in the metal layer for the $\mathrm{Al}_{2} \mathrm{O}_{3} / \mathrm{Al}$ interfacial system has been shown to affect time dependent crack propagation, as well as the fast fracture properties. Specifically,

- For fast fracture, thicker, less constrained layers show higher fracture toughness for near interfacial (alumina) failure.

- Highly constrained layers exhibit better fatigue properties at low driving forces in the form of higher fatigue thresholds; however, at higher driving forces the failure mode may change to crack growth in the alumina resulting in substantially less crack growth resistance. 
- Under static loading in a moist environment, cracks leave the interface and propagate into the oxide only for thin (highly constrained) layers; however, this mechanism is inactive for thicker (less constrained) layers.

While previous studies have shown that increasing constraint in alumina/aluminum interface systems produces higher strength joints [2], the current study shows that although interfacial fatigue thresholds are also improved, flaw tolerance is essentially reduced by lowering the fracture toughness and activating time dependent crack propagation in the alumina (by both cyclic fatigue at high driving forces and static fatigue in a moist environment).

\section{ACKNOWLEDGMENTS}

This work was supported by the Director, Office of Science, Office of Basic Energy Sciences, Materials Sciences Division of the U.S. Department of Energy under Contract No. DEAC03-76SF00098.

\section{REFERENCES}

1. J. M. McNaney, R. M. Cannon and R. O. Ritchie, Int. J. Fract., 66, 227-240 (1994).

2. B. J. Dalgleish, K. P. Trumble and A. G. Evans, Acta Metall., 37(7), 1923-1931 (1989).

3. D. Korn, G. Elssner, H. F. Fischmeister and M. Rühle, Acta Metall. Mater., 40, S355-S360 (1992).

4. G. Elssner, T. Suga and M. Turwitt, J. De Physique, 46, C4-597-C4-612 (1985).

5. A. G. Evans and M. C. Lu, Acta Metall., 34(8), 1643-1655 (1986).

6. A. G. Evans, B. J. Dalgleish, M. He and J. W. Hutchinson, Acta Metall., 37(12), 3249-3254 (1989).

7. A. G. Evans and B. J. Dalgleish, Acta Metall. Mater., 40, S295-S306 (1992).

8. I. E. Reimanis, B. J. Dalgleish and A. G. Evans, Acta Metall. Mater., 39(12), 3133-3141 (1991).

9. C. F. Shih and R. J. Asaro, J. App. Mech., 55, 299-316 (1988).

10. J. W. Hutchinson and Z. Suo, Adv. App. Mech., 29, 63-191 (1992).

11. M. R. Turner and A. G. Evans, Acta Mater., 44(3), 863-871 (1996).

12. B. J. Dalgleish, M. C. Lu and A. G. Evans, Acta Metall., 36(8), 2029-2035 (1988).

13. J. R. Rice, J. App. Mech., 55, 98-103 (1988).

14. A. G. Varias, Z. Suo and C. F. Shih, J. Mech. Phys. Solids, 39(7), 963-986 (1991).

15. B. J. Dalgleish, E. Saiz, A. P. Tomsia, R. M. Cannon and R. O. Ritchie, Scripta Metall. Mater., 31(8), 1109-1114 (1994).

16. M. C. Shaw, D. B. Marshall, B. J. Dalgleish, M. S. Dadkhah, M. Y. He and A. G. Evans, Acta Metall. Mater., 42(12), 4091-4099 (1994).

17. J. M. McNaney, R. M. Cannon and R. O. Ritchie, Acta Mater., 44(12), 4713-4728 (1996).

18. F. Gaudette, S. Suresh and A. G. Evans, Metall. Mater. Trans., 30A, 763-769 (1999).

19. R. M. Cannon, B. J. Dalgleish, R. H. Dauskardt, T. S. Oh and R. O. Ritchie, Acta Metall. Mater., 39(9), 21452156 (1991).

20. T. S. Oh, R. M. Cannon, J. Rödel, A. M. Glaeser and R. O. Ritchie, in Interfaces in Polymer, Ceramic, and Metal Matrix Composites, ed. H. Ishida (Elsevier, 1988) pp. 567-581.

21. I. E. Reimanis, B. J. Dalgleish, M. Brahy, M. Rühle and A. G. Evans, Acta Metall. Mater., 38(12), 2645-2652 (1990).

22. T. S. Oh, R. M. Cannon and R. O. Ritchie, J. Am. Ceram. Soc., 70(12), C-352-C-355 (1987).

23. J. C. Card, R. M. Cannon, R. H. Dauskardt and R. O. Ritchie, in Joining and Adhesion of Advanced Inorganic Materials, ed. A. H. Carim, D. S. Schartz, R. S. Silberglitt and R. E. Loehman (MRS, 1993) pp. 109-116.

24. C. J. Gilbert, Y. S. Han, D. K. Kim and R. O. Ritchie, Ceram. Inter., 26, 721-725 (2000).

25. R. O. Ritchie and W. Yu, in Small Fatigue Cracks, ed. R. O. Ritchie and J. Lankford (TMS-AIME, 1986) pp. 167-189.

26. R. H. Dauskardt, M. R. James, J. R. Porter and R. O. Ritchie, J. Am. Ceram. Soc., 75(4), 759-771 (1992).

27. S. W. Freiman, K. R. McKinney and H. L. Smith, in Symposium of Fracture Mechanics of Ceramics, ed. R. C. Bradt, D. P. H. Hasselmann and F. F. Lange (Plenum, 1974) pp. 659-676. 